https://helda.helsinki.fi

\title{
Siberian Software Developers
}

\section{Indukaev, Andrey}

Duke University Press

2019-05

Indukaev , A 2019 , Siberian Software Developers . in M Biagioli \& V Lepinay (eds), From

Russia with Code : Programming Migrations in Post-Soviet Times . Duke University Press, pp. 195-212 . https://doi.org/10.1215/9781478003342-008

http://hdl.handle.net/10138/322064

https://doi.org/10.1215/9781478003342-008

acceptedVersion

Downloaded from Helda, University of Helsinki institutional repository.

This is an electronic reprint of the original article.

This reprint may differ from the original in pagination and typographic detail.

Please cite the original version. 
Indukaev, Andrey. 2019. « Siberian Software Developers ». In From Russia with Code: Programming Migrations in Post-Soviet Times, edited by Mario Biagioli et Vincent Lepinay. Durham, London: Duke University Press. 
SECTION 2 - Outward-Looking Enclaves 


\section{Siberian Software Developers}

Andrey Indukaev

To most foreigners, Siberia is a vast, barely inhabited, fatally cold region-an exotic sight best appreciated from the windows of the Trans-Siberian Railway. At the same time, all around the world one can find IT entrepreneurs and managers who see Siberia as a place populated by key practitioners. It is not uncommon for IT firms to have a Siberian subcontractor, a long-term partner, a supplier, or to establish an R\&D center in the region. Large international companies as well as small and medium-size enterprises from such places as the US, South Korea, Germany, France, Switzerland, and several former USSR countries rely on their Siberian partners.

The Siberian IT sector may be seen as an exception to the alleged Russian incapacity to gain social and economic benefits out of technology. Loren Graham, a renowned specialist in Russian science and technology studies, suggests in his last major book that for centuries the country's technological development has been plagued by the very same pattern of failure: Russia is able to give birth to outstanding inventions but permanently fails to turn them into innovations, which is to say, to adopt them at a large scale and, in consequence, to reap the technological and economical reward (2013). The author claims that "Russians have never [...] fully adopted the modern view that making money from technological innovation is an honorable, decent, and admirable thing to do," and that this "may be the most important of all" factors that contribute to the unfortunate Russian pattern of failed innovation (Ibid. 103). Graham's claim is supported by interviews and conversations with Russian scientists who manifest negative attitude towards any form of commercial activity as well as by his observation that almost no Russian students in science and engineering have a desire to create a start-up.

The present paper is based on a set of interviews with IT professionals in two major Siberian cities, Novosibirsk and Tomsk. The collected data may be seen as both confirming and challenging the Graham's diagnosis. Former soviet researchers in Siberia have adopted business logic and are able to run a successful company. However that logic is not the one that Graham and other innovation scholars refer to and which is typically associated with innovation. Siberian entrepreneurs set themselves apart from startups and venture capital: business models combining extremely high risk with potentially explosive profits. Nevertheless, even if one accept the idea that only a system that produces start-ups with 
exponential growth potential is the key to technological development, the IT firms in Tomsk and Novosibirsk create what is an absolute prerequisite for the appearance of such a system. Venture capital industry is unimaginable without a pool of competent professionals and the basic innovation infrastructure. In Russia that infrastructure is mainly created within the framework of the state's innovation policy. I will show that Siberian IT firms contribute to the development of the instruments of the federal innovation policy and to the training of highlyskilled workforce.

The chapter starts by an outline of the key features of the IT sector in Tomsk and Novosibirsk and the description of their immediate environment, such as universities and research institutes. Then I show how the key players in the sector, all having background in Soviet research institutions, combine business logic with a specific professional ethos routed in their past, valuing high technical skill and complex problem solving more than business growth and profit-seeking. Finally, I show how the IT firms contribute to local technological development through teaching and through developing local instruments of the federal innovation policy and argue that this activity is related to the professional ethos of the local community.

\section{The IT Sector in Novosibirsk and Tomsk}

Initially labeled a "pseudo-science," computer science struggled during the Soviet era but eventually managed to become a legitimate and active scientific and technological domain (Gerovitch 2002, Tatarchenko, this volume). Siberia and especially Novosibirsk played an important role in this process. The computer center situated in Akademgorodok (the "city of science" next to Novosibirsk) was, in the 1980s, one of the largest multiple-access computing centers in the country, with up to 1,300 employees (Ilyin and Marchenko 2014). The programming community in Akademgorodok promoted advanced research and, despite the cold war climate, was well connected with the broader international scientific community (Tatarchenko 2013). Similarly, computer science developed in Tomsk from the late 1950s on (Yevtushenko 2003), though in a less independent fashion, with programming being closely related to radio physics and applied research for electronic and defense industry needs.

By the time the Soviet Union collapsed in 1991, Novosibirsk and, to a lesser extent, Tomsk were host to a significant programming community distributed over numerous fundamental and applied research teams. However, the following years were characterized by a considerable curtailment of research funding. Along with other scientific fields, the programming community fell on hard times, losing both state support and industry contracts 
for applied research (Graham and Dezhina 2008); while most of the academic research institutes survived the crisis, an important number of computer scientists emigrated. This chapter does not follow diasporic trajectories and focuses instead on those community members who continued to do research or commercial programming in Novosibirsk and Tomsk.

I will now outline the general features of computer science research in these two cities. The output of scientific activity of computer scientists from Tomsk and Novosibirsk can be assessed by analyzing publication data from the Web of Science database. In general, Russia is not an active source of publications in computer science. Only about fifteen thousand publications in computer science have authors with Russian affiliations, while the USA has about half a million publications in the field. Yet by Russian standards, Novosibirsk is an important computer science research center counting more than 1,600 publications, outranked only by Moscow and Saint-Petersburg. The first publication listing a Novosibirsk affiliation appeared in 1973. 595 computer science articles (40\%) that are cited at least once and 92 $(6 \%)$ that are cited more than ten times. Tomsk is less prominent but still visible, figuring in the institutional affiliation of 300 computer science publications. Of those articles, $54(18 \%)$ are cited at least once and seven (2\%) are cited more than ten times. It is not surprising that Novosibirsk is ranked ahead of Tomsk as a research site: Novosibirsk is the third largest city in Russia with about one and a half million inhabitants, while Tomsk is about three times smaller.

An important feature of Tomsk is that despite being a relatively small city it performs quite well as an educational center. The number of students per 10,000 inhabitants is the highest in Russia, excluding Moscow and Saint-Petersburg (Bychkova and Popova 2012, 227). Tomsk State University and Tomsk Polytechnic University hold, respectively, the tenth and twelfth places among Russian universities included in the QS University Rankings for 2014/2015, and are outranked only by universities from Moscow, Saint-Petersburg, and Novosibirsk. The most active research in computer science in Tomsk is carried out by the following universities: Tomsk State University, Tomsk State Polytechnic University, and Tomsk State University of Control Systems and Radio-electronics. These three institutions generate the majority of the city's publications in the field.

Novosibirsk is also an important educational center, but most of the computer science authors there are affiliated with one of Akademgorodok's research institutes. Local universities also contribute computer science publications, but to a lesser extent. This can be explained by the fact that-in keeping with the initial design of Akademgorodok's education 
and research system-university faculty were often affiliated with its research institutes. In sum, Novosibirsk is a large city with an important research community in computer science, and while Tomsk is smaller and less active in terms of research metrics, it is still an important training center in the field.

Both cities also feature active private IT sectors. Novosibirsk is definitely an important software development center. According to data presented by RUSSOFT, the city is one of four Russian locations listed in the "Top 100" list of global outsourcing destinations (RUSSOFT, 2014). It is known that both Novosibirsk and Tomsk are "popular destinations for development centers since the 1990s" (Zhikharevitch, this volume). It is difficult to evaluate the size of the IT sectors in Novosibirsk and Tomsk; however, an estimation of the number of developers within a city can be made. According to the RUSSOFT report, there are about 430,000 software developers in Russia (RUSSOFT, 2014, 43). RUSSOFT estimates that $5 \%$ of them are in Novosibirsk, which translates to approximately 20,000 developers (Ibid. 119). Without having such data for Tomsk, one can use the comparative ratio of city inhabitants to estimate the number of programmers at one-third the population, which equates to approximately 7,000 developers ${ }^{1}$.

\section{Origins and Character of the Siberian IT Sector}

Both cities host firms with a strong peer reputation for their professionalism. Most of these firms appeared shortly after the collapse of the Soviet Union, founded by programmers who had previously worked in local research centers and universities. In Novosibirsk, several of these firms play a central role in a nonprofit partnership of IT companies called SibAkademSoft—a well-respected organization that closely interacts with regional authorities and the Academy of Sciences to promote the interests of the IT sector. Among other initiatives, SibAkademSoft played an active role in establishing the local technopark.

While firms that emerged from research institutions are not the only players in the local software sector, they provide an example, or perhaps even an exemplar, for local programmers and entrepreneurs, informing both their business models and ethos. Most of them do not offer products for the "mass market" and individual users but develop complex customized products for corporate clients (often also in the IT sector), or do software

\footnotetext{
${ }^{1}$ I tested this estimation by looking at the number of users of the popular Stackoverflow website-a "question and answer site for professional and enthusiast programmers." The database of Stackoverflow users developed by our project allows us to count the number of individuals who, when establishing an account, listed Novosibirsk and Tomsk as their location. Novosibirsk hosts 46 users and Tomsk 14-as expected the ratio is approximately 3:1.
} 
development for other firms (in Russia and abroad), who own and distribute the final product. According to a RUSSOFT survey, in $36 \%$ of cases Siberian firms prioritize export over the domestic market, the highest percentage among all Russian regions (RUSSOFT, 2014, 62). This international orientation is, I believe, an index of the quality of Siberian software.

The developers in Novosibirsk and Tomsk often claim that their business model relies on the quality of their work and on the complexity of problems that they can solve. As Irina Trofimova, the director of a Novosibirsk firm, explains: "It is a high added value, a unique product, normally big projects where we can show off $[\ldots]$ our unique competences." Indeed, Irina Trofimova's firm works in very specific domains-virtual reality systems for training simulators as well as hardware and software for TV broadcasting — that require high reliability and real-time graphics. In fact, her employees co-author professional publications with academic and industrial scientists from Stanford University, Sony Pictures Imageworks, NVIDIA, and other leading organizations from industry and academia (Fernando 2004).

Eugene Petrov, the head of another firm in Novosibirsk, also emphasizes their uniqueness and specialization: "we consider ourselves to be rare birds, we do system programming." His firm specializes in compilers, a very specific product for professional programmers that requires a high level of skill to develop. Similarly, Elena Semenova, project manager from another firm, albeit with a less sophisticated specialization-mostly outsource development—still emphasizes the fact that it develops projects in specific and complex domains such as bioinformatics and system programming.

Former soviet research collectives had to significantly change their way of working in order to become a successful IT firm. They had to become capable to respect the deadline and to contend their passion for inquiry in order to timely provide expected result. That required to go through quite a challenging learning process. For Irina Trofimova and her firm it was really difficult to abandon the way of working inherited from their past role of a soviet researcher:

It was a tough transition, because people who had joined the company had $\phi$ researcher's mentality. [...] for them it is not typical to do things in time. They always get absorbed by exploring stuff. That's interesting, but it is difficult to get a result acting this way, and in business you need the result. At our company it was quite painful [...] because when you plan one time frame [for developing a product] but you only manage to make it in a longer time frame, you get low profit. 
The understanding of the basic rules of doing business, namely the profitability considerations, created some distance between the former researchers in business and those who stayed in academia. In the 1990s, many of these companies had their office space on the premises of research organizations-a spatial closeness that often continues to this day. However, firm managers do not collaborate much with researchers. In the past, some businessmen tried to work with academic researchers. For example, Eugene Petrov's firm is still located in the building of a research institute, and he mentioned several attempts to work with researchers from the institute, and does not exclude similar attempts in the future. However, only one such project, a prototype development for a state enterprise from the space sector, which became profitable but was eventually abandoned by the researchers, who did not have the skills or willingness to handle the clients' demands, or their delays. Petrov appeared to be the most optimistic concerning the collaboration with researchers, most of the respondents believed that research institutes are not of much interest businesswise. So, one could conclude that former soviet researchers have adopted the business logic of profitseeking and have transformed into innovative businessmen emancipated from the burden of their past and the critical attitude towards money.

However, the situation seems to be more controversial when one focuses on the IT firms' attitude to their soviet past and at their general attitude towards the research community. For instance, Eugene Petrov, despite his negative business experience with researchers, considers himself culturally close to them: "We do not interact with institutes on practical matters, still we have some cultural interaction, we are in the cultural milieu here." This mix of cultural kinship and business distance characterizes almost all the companies I have studied. Some firms build partnerships with academic researchers, but these partnerships are not directly related to business and are not motivated solely by commercially-oriented considerations. For example, Elena Semenova's firm developed a bioinformatics project in direct collaboration with local scientists, but in the end the firm had to accept the researchers' mentality rather than the other way around, and the project became almost non-commercial: "One can say it is our scientific hobby." While not all firms in Novosibirsk collaborate with researchers, the proximity to a large research community tends to orient their specialization. In Elena Semenova's words: "Being in Akademgorodok without doing something involving some research element-it would be strange, [as] there are lots of institutes around."

The proximity to the research community also influences the very core of the studied IT professionals' business specialization which they deduce from their past experience of research work. Irina Trofimova, Elena Semenova, and Eugene Petrov all work for different 
firms with roots in Soviet research institutes. For them, their firm's origin determines its specialization:

We have one serious project related to system programming (...) it's our subject, because the company's founders they are from the [Soviet] supercomputer project. (Elena Semenova)

Our laboratory [at a research institute] was named "Machine graphics laboratory"... We were specialists in this domain and we keep this specialization.

(Irina Trofimova)

When you design a computer (... ) you should [often] create the compiler. K1 group [a group formed around an exploratory chip development project in 1986] worked on it. Its development was continued [by our firm]... it's still our main specialization.

(Eugene Petrov)

Firms with similar background and orientation can be found in Tomsk as well. Igor Andreev is the head of a company that specializes in video codecs (standard video compression formats), which is well known among professionals worldwide. The firm was founded by researchers from the Special Design Bureau "Optika," which was part of the Academy of Sciences. Stanislav Pavlov, one of its founders, was a researcher in the Laboratory of Digital Television, so the company's specialization reflects, in part, his own academic background. Tomsk's local universities seem to have played the role of "incubators" in equal measure with the research centers, as evidenced by Igor Andreev's narrative of the long genealogy of Tomsk's video engineering community:

If we talk about the foundations... The first TV signal was received in Tomsk in 1923. Tomsk was the third city to launch analog television, after Moscow and SaintPetersburg, in 1953. It was done by Polytech [Tomsk Polytechnic Institute, later becoming University]. Those who did it founded TUSUR [Tomsk State University of Control Systems and Radio-electronics] and they taught those who taught Stanislav who taught me. 
Vitaliy Alexandrov, the head and founder of another Tomsk-based software firm, was trained as an engineer and worked at what, during the Soviet period, was known as the Tomsk Polytechnic Institute. He considers that he is still working in his degree field: "I was trained as an engineer in circuit design. [...] I am among the rare people who stayed in the field." His firm's specialization is closely related to the research background of its founders and employees, who are also former Soviet applied researchers.

The business specialization of these firms, however, is not shaped exclusively by their founders' scientific background, their proximity to academic centers, or the perspectives they acquired by being trained in Soviet research institutions. Interviewees often explain such specialization in high-end complex products in terms of what can be seen as a market strategy: firms specialize in complex problem solving to avoid overlap and competition. As the heads of some firms told me:

By working on a problem that is complex in terms of engineering, we reduce the number of potential competitors. (Igor Andreev)

One cannot be in competition with students, [...] they are ready to create a site for 5,000 rubles. In our case, with rent, officially declared salary, and taxes, it costs us no less than 50,000 . So we try to do projects where we can be unique, [...] specialized projects. (Alexey Ivanov)

However, we noticed that the specialization of the firm is always presented as something that has an inherent, non-business-related value. Interviewees often describe their job as doing work that is "true," "serious," and "interesting." In some cases, programmers state that this abstract "gusto" has a clear priority over profitability:

We try to do an interesting product, based on in-depth understanding of the domain we work in. It is interesting. And if we see then that our clients are also interested in our developments, we are pleased. And it is also not bad if there are some financial outputs when we release. (Vitaly Alexandrov)

Many heads of firms contrast their approach to the more common profit-driven ways of doing business, which some associate with the word "entrepreneur": 
So the orientation toward entrepreneurship appeared not because I am inherently an entrepreneur but because we had no job to do [after the drop of funding of the institute where Vitaly used to work]. I still perceive myself more as an engineer than as an entrepreneur. It may explain the orientation of our company. (Vitaly Alexandrov)

Others contrast their work to that of "young start-ups":

We do not have a lot of competitors. Because most of young and wannabe startups have on goal of making a fast buck and we do things that required years of R\&D. (Igor Andreev)

And yet others explain that money-driven approach does not fit them:

[D]oing business only for doing money is not an approach that I support. One can create a firm of 5-10 people and have a great life, have enough revenue for those 10 persons and the firm will be great, while it can be not worth making it grow to 1000 persons and then sell it. (Irina Trofimova, addressing students during a public lecture)

What emerges from the interviews is an understanding of a firm's excellence based on the complexity of the problems it solves and the elegance and quality of those solutions. This goes hand in hand with an explicit refusal of profit-maximization logic. The firms' roots in the culture of former Soviet researchers and, to a lesser degree, its ideological proximity to institutes and universities are among the factors that shape this business approach.

One can clearly see that the Siberian IT businessmen have not completely abandoned the critical attitude towards profit making, startups and even the concept of entrepreneurship, the very attitude that, according to Loren Graham, may be one of the main reasons of Russia's failure to modernize its technology and economy. At the same time it is hard to perceive these successful and respected technological businesses as a treat to Russia's modernization. One of the reasons of that mismatch may lay in the fact that one should not necessarily embrace the business logic obsessed with explosive growth in order to contribute to technological development. Due to some spectacular success that business model promoted by venture capital has brought to life in some countries, the startups are now seen, by so many, as a key element of technological development and innovation. Martin Kenney suggests that it is the reason why innovation policy today often overlooks "nice growth firms," that is to say, 
organizations with business models focused on competence development and technical excellence rather than strategies based on a "high risk versus explosive growth" model promoted by venture capitalists (2012). The firms I have described match the "nice growth" model. They produce high-quality software and are integrated in international technological circuits and contribute to the country technological development at least by that.

However, those firms could be seen positively even if one adopt a point a view that the only key to technological development is a venture capital model - a system aiming the endless creation of new business seeking (sometimes with success) explosive growth. Indeed, a historically informed view on the development of the venture capital industry shows that the desired system appears not in a vacuum, but thanks to "a set of conditions that develop in the pre-emergence phase $[\ldots]$ because they provide the resources necessary for the emergence [of the venture capital industry] to be successful" (Avnimelech, Kenney, and Teubal 2005, 197). In the next section I am going to show that IT firms in Novosibirsk and Tomsk contribute to the training of the high-skilled professionals in their field, whose existence is an unquestionable prerequisite for any scenario of the region's technological development. Moreover, these firms not only use the innovation infrastructure created by the state but actively contribute to its efficiency, especially through supporting young businesses. One of the main reasons why IT firms contribute to the region technological development is their specific attitude to the business routed in their soviet past.

\section{Firms and University Teaching}

The lack of well-trained IT specialists is often presented by IT professionals in Tomsk and Novosibirsk as one of the mains challenges that their businesses face. That may be surprising, taking into account that both cities are major educational hubs. However, as Marina Fedorova comprehensively explained in the review of the literature done in her chapter on Yandex, the training of IT professionals is the problem inherent to the domain, where there is no conventional definition of professional standards and the on-site training is a crucial part of becoming a programmer (Fedorova on Yandex, this volume). The Siberian IT firms have a solution to this problem that serves as much their recruitment needs as the interests of the community in general.

The firms I have studied do not generally receive a direct technological advantage from their proximity to research organizations. They do, however, still have a close relationship with universities and research institutes, albeit of a specific kind: their employees often teach and supervise students' coursework. 
In Tomsk, firm employees are often affiliated with universities, and although many of Novosibirk's software developers are formally affiliated with the local research institutes rather than the universities, they are still involved in teaching because with the creation of Academgorodok, university teaching is provided by research institute employees. But why do firm employees take on the additional burden of teaching? A possible explanation is that universities seek private-sector specialists to teach up-to-date knowledge to their students. Maxim Antonov, an R\&D director in a Novosibirsk firm and an administrator and teacher in one of the city's top universities, describes this situation in a very revealing way. For him, the place of researchers in the initial Akademgorodok setting, where "people from science, with real experience, should teach, not full-time teachers," is now taken by people from firms:

So, a person who is doing research, and now that means can earn money with research, he knows what is needed for it, and he will teach people how to do up-to-date stuff. [...] And taking into consideration the fact that nowadays the informatics in Academy is not in a good condition, institutes cannot keep top level specialists in informatics-there's no money there, with Academy's [Russian Academy of Sciences] salaries, no good programmer will work there.

This quote illustrates the idea that competences are now concentrated in the IT industry. Moreover, it resonates with our description of the local firms' specific attitude toward business. Antonov sees himself and his firm as the heirs of Akademgorodok's important and distinct research tradition, its excellence, its applied orientation, and its engagement in the formation of professionals-researchers in the past and programmers in the present.

It is also interesting to track the reference to "we" in his narrative and, thus, his complex self-identification: "We invite staff to teach students from exactly the same sort of companies as ours [...]. We have people from about ten companies or more teaching at our [university] department." Both "we" and the second "our" most probably refer to the department faculty at a local university, where Antonov teaches. The first "ours" refers to the company where he works. Somehow the role of a company employee and a university administrator are so tightly bound together that it gives the impression that for Antonov the work within a firm and the formation of students belong to the same coherent continuum of activities, as it was at a research institute. And one may extrapolate that such a hybrid role of "business programmer engaged in academic teaching" characterizes not only Antonov's firm but several others, since he mentions "about ten companies or more." 
Antonov's complex self-representation does not in any way contradict the fact that people from local firms are active in education also because of their need to identify and recruit competent employees. Given business specialization in complex projects, these companies need highly qualified programmers. In some cases (as with Yandex), such training is primarily provided in-house, while in Novosibirsk it is done at the university, albeit provided by industry specialists. As Antonov explains: "I can teach it only at a university. And it is only me who can do it. I've tried many times to find someone trained as I need, but the science that I need is not taught anywhere."

The described pattern is not exceptional, since there are many cases where IT firms tackle the problem of the lack of qualified workforce through activities that contribute to the development of the IT community in general. The Yandex Data School is free and open to anyone who can pass the exams; moreover it collaborates with many Russian universities' departments related to IT, contributing to teaching and curricula design. And one do not have to be the Russian Google to adopt this attitude to programmers training - Vladivostok's IT firms, without being industry leaders, were actively involved in teaching (Masalskaya and Vasilyeva, this volume). In Vladivostok's case this spontaneous proximity between industry and education was almost destroyed by the federal government innovation policy. In the case of Tomsk and Novosibirsk the federal innovation policy has not affected the bond between IT firms and education. Moreover, local IT communities contributed to the creation of the instruments of the innovation policy and continue to shape them in such a way that these instruments have become attractive to innovative businesses.

\section{The Software Community and State-promoted Innovation}

The engagement of IT firms of Novosibirsk and Tomsk in the education contributes to my argument about the positive effect of local IT community on the technological development. The other achievement of the community is, at the first sight, even more spectacular but requires a careful examination. The companies that I study are now associated with the relative success of the local state-supported institutions aimed at promoting innovative activity. This success is assessed by official controlling authority. However, I will show that this assessment, based on the performance indicators, may be misleading. Nevertheless, the IT firms I study contribute to the proper functioning of the innovation infrastructure elements created by the state. 
In 2004-2005, the Russian federal government began to take a more active role in national and regional economies through its innovation and modernization policy. One of the earliest steps was the creation of Special Economic Zones (SEZ) (OECD 2006). When the Ministry of Economic Development and Trade called for SEZ proposals, both Tomsk and Novosibirsk responded, but only Tomsk was selected. The specific SEZ that was awarded to Tomsk is a "Technical Innovation Zone", which gives companies that are given resident status tax and custom advantages. Two firms from the sample I studied are SEZ residents.

Yet Novosibirsk's effort to submit a proposal was not in vain. The mobilization of both the local government and the business community eventually gave birth to a different but related project-a technopark-within the framework of a large program supervised by the Ministry of Communications and Mass Media. With the launch of the ministry program in 2006, Novosibirsk's Akademgorodok became a candidate for the location of a technopark, and in December 2007 was selected to host it. The local business community and SibAkademSoft played an active role in the program initiation (Artyushina and Chernykh 2012, 355).

The SEZ in Tomsk and the technopark in Novosibirsk are both part of large governmental programs engaged in many regions throughout Russia. Crucially, in 2014 both projects were officially recognized as the best among their counterparts. The recent report published by the Audit Chamber of the Russian Federation (Schetnaya Palata Rossiyskoy Federatsii), ranked the SEZ in Tomsk as the best among all specials zones of its specific type, “Technical Innovation Zone” (Schetnaya Palata Rossiyskoy Federatsii 2014, 106). And again according to the Audit Chamber, the technopark in Novosibirsk is the most effective among all the technoparks created in Russia (Schetnaya Palata Rossiyskoy Federatsii 2015, 67). However, it is easy to see that almost all metrics that contribute to that are related to one phenomenon - SEZ and technopark were able to attract profitable firms employing significant workforce. Indeed the evaluation is based on indicators such as the revenue of the technopark's residents and also on the number of employees. These indicators show that the SEZ and technopark employ a sizeable, highly skilled workforce (up to 4,000 in Novosibirsk, and 1000 in Tomsk) and are economically viable (218.5 million rubles in tax payed in 2012 by Tomsk SEZ residents, and 823 million rubles collected in 2014 from the residents of Novosibirsk's technopark).

The number of individuals employed by the residents of those organizations is often reported as "the quantity of created jobs". This, however, may be misleading since residents already employed most of their workforce before joining the technopark and SEZ. The taxes 
payed by the residents and their revenues are also the metrics that do not make distinction between the eventual positive impact of the technopark and SEZ and the economic performance of the residents that is unrelated to activities of those organizations. So there is no precise data about effect of the technopark and SEZ on the local technological development.

However, many facts support the view that these organizations are effective in fulfilling their mission, or, at least, have the potential for it. First of all, the very fact that active and successful IT firms decided to be associated with technopark and SEZ signifies that these instruments of the innovation policy are relevant to business needs. This is clearly a good sign, taking into account the troubled track record of many other technoparks and SEZ across Russia and, in general, the Russian tendency to design innovation policy tools in a topbottom way, making them irrelevant to business needs, the problem that may in part be illustrated by Skolkovo's mixed performance (Simonova, this volume). Second, a least in Novosibirsk, IT firms are more than mere users of the technopark, but actively shape the way it works.

One of the important elements of Novosibirsk's technopark is the system of support for the new businesses, including a business incubator and a two week acceleration program (formerly known as Summer and Winter School of Akadempark) taking place twice a year. According to one of the high-ranked managers of the technopark, the acceleration program is "unique [...] because of the size and the composition of the pool of experts, who are practitioners, not business coaches [...] but people who had learned in the school of hard knocks while building their business, and are ready to share their experience" (Petr Lvov). Indeed, managers from techopark's residents, including IT firms that I study, volunteer as experts for the accelerator, without having such an obligation in the residence agreement. The residents also provide mentorship for startups at the techopark's incubator. According to the manager cited above, the "mentorship and the support from experts are among the reasons why people come here [to the incubator]" (Petr Lvov). In general, the residents are open to dialogue with startups form the incubator: "if you [a startup] want to communicate with any manager of an Akadempark's resident, we will organize a meeting, no problem" (Petr Lvov). This readiness to help the technopark and to contribute to the development of new businesses is, at least in part, related to the local general attitude to the business. Such a situation is possible "thanks to the milieu we have here - at Akademgorodok, at Akadempark" continues the manager of the technopark, since "local firms want to develop technological entrepreneurship milieu here" (Petr Lvov). In the case of Tomsk, I have less evidence on local 
IT firms' engagement in the development of the SEZ. However, both SEZ residents from my sample are partners of a quite active local business incubator.

As Simonova has shown in her study, the top-down design of Skolkovo has led to its mismatch with the needs of innovative business, making it difficult to this costly project to become fully functional. The hackspace Neuron, designed by entrepreneurs, fits their needs and is an example of active and successful environment for innovative businesses (Simonova, this volume). The case confirms an observation done by many scholars. Indeed, the governments who design instruments aiming innovative entrepreneurship and technological development in a top-down manner and without understanding of the entrepreneurial process fail to achieve the desired goal. These are reputed to be the two most important pitfalls of the innovation policies in numerous countries (Lerner 2009). While one does not have sufficient proof of the efficiency of innovation infrastructure in Tomsk and Novosibirsk, the very fact that successful local business are closely associated with the technopark and SEZ suggests that these innovation policy instruments have at least avoided those most frequent errors. I suggest that it would not have been possible without a local IT community sharing a particular professional ethos influenced by the soviet past, especially the "Akademgorodok milieu" in Novosibirsk.

\section{Conclusion}

In this chapter, observed a business community whose existence and success both confirms and questions the diagnosis that Russia's innovation capacity has received from many experts and researchers. Russians, particularly researchers, may be somehow critical towards business and that hampers country's technological development.

The IT sector that I studied in Novosibirsk and Tomsk may symbolize that Russia is gradually recovering from this old disease, comprehensively described by Graham (2013). Indeed, many successful and internationally renowned IT firms in these cities were founded by the very same soviet researchers whose disregard towards commercial activity is believed to hamper Russia's innovation capacity. The founders and managers of these firms take profitability seriously, they had to adopt the way of working that is clearly distinct form what they were used to while being researchers. They also become aware of the problem Graham has described that most of their fellow soviet and post-soviet scientists are unable to adopt even a tiny bit of business logic.

However, it is only a part of the story. It would be misleading to present the IT community in Tomsk and Novosibirsk as a result of a successful emancipation of the former 
soviet researchers form the long lasting aversion that Russians have towards making money through technological entrepreneurship. Despite the lack of business ties with research many IT firms' founders and employees present themselves as culturally close to the academic community. Also, emphasizing high technical skill and complex problem solving, many IT firms present them both as a business strategy and a value-driven decision, closely related to the roots of the local IT community in Soviet research institutions. For the leaders of the local IT sector embracing business logic does not mean seeking growth at all price. Many of them explicitly refuse the logic of profit maximization, extensive growth and even do not want to identify themselves as entrepreneurs, while in fact managing a successful private firm. Also, they are not extremely enthusiastic towards what may be called a start-up or venture capital business model: high-risk with a chance of huge profits.

Business leaders of the IT sectors in Tomsk and Novosibirsk do not fully adopt the attitude that some perceive as the essence of technological entrepreneurship and the main ingredient of the innovation process. However, that it does not necessarily mean that IT sectors in those cities are unable to do their part in promoting the country's technological development. First of all, the innovation and technological development do not have to be defined exclusively through successful commercialization following venture capital prescribed high-risk business models. Second, IT firms that I portray in this chapter have a positive impact on the region's technological development even if one admits the idea that start-ups and venture capital are the principal sources of the latter. Indeed, the IT community that I describe is actively engaged in the training of highly-skilled professionals, this engagement motivated by the community's value-driven attitude toward business and its cultural proximity to the research and education. Moreover the very same professionals took an active role in designing local instruments of innovation policy and contribute to their everyday functioning and, specifically, to the mentoring of local startups, making those instruments adapted to the needs of the business, not those of bureaucrats.

By contributing to the training of highly skilled programmers and to the development of the local innovation infrastructure, IT firms in Novosibirsk and Tomsk provide the resources that are an essential prerequisite for what many experts see as a key for technological and economic development and what is a stated goal of the innovation policy: a system that sustainably produces new high-technology businesses, some of them manifesting explosive growth. Surprisingly, Siberian IT professionals do it because of the very same set of values originating in the Soviet past that makes them critical towards the logic of profit maximization and the way of doing business associated with venture capital. In a way, the 
attitude that is supposed to hamper Russia's technological development may actually make it happen. Still, while Siberian IT firms create resources that are essential to that process, one cannot guarantee that it will indeed take place at a large scale - Russian context is unfavorable to innovation for multiple reasons. But should we put the blame on this peculiar way of doing business that former soviet researchers have adopted? 


\section{References}

Artyushina, Anna, and Anna Chernykh. 2012. "Sotsial'nye 'Portrety' Tekhnologicheskikh Predprinimateley: Sluchay Novosibirska I Novosibirskoy Oblasti." Saint Petersburg: Center for Science and Technology Studies EUSpB.

Avnimelech, Gil, Martin Kenney, and Morris Teubal. 2005. "A Life Cycle Model for the Creation of National Venture Capital Industries: Comparing the US and Israeli Experiences." In Clusters Facing Competition: The Importance of External Linkages, edited by Elisa Giuliani, Roberta Rabellotti, and Meine Pieter Vav Dijk.

Bychkova, Olga, and Evgeniya Popova. 2012. 'Sotsial'nye 'Portrety' Tekhnologicheskikh Predprinimateley: Sluchay Tomska I Tomskoy Oblasti.” Saint Petersburg: Center for Science and Technology Studies EUSpB.

Fernando, Randima. 2004. GPU Gems: Programming Techniques, Tips and Tricks for RealTime Graphics. First Edition. Boston: Addison-Wesley Professional.

Gerovitch, Slava. 2002. From newspeak to cyberspeak: a history of Soviet cybernetics. Cambridge, Massachusetts: The MIT Press.

Graham, Loren R., and Irina Dezhina. 2008. Science in the new Russia: crisis, aid, reform. Bloomington: Indiana University Press.

Ilyin, Valery, and Michail Marchenko. 2014. “Al'ma-Mater Sibirskoy Vychislitel'noy Informatiki [Alma Mater of Siberian Computational Informatics].” Science in Siberia 21 (2956): 4-5, 8 .

Kenney, Martin. 2012. "Venture Capital Has a Role, But Do Not Forget Nice Growth Firms." In Growth Enterprise Review, Government of Finland, Ministry of Education. Helsinki.

OECD. 2006. OECD Economic Surveys: Russian Federation. Vol. 17. Paris: OECD.

Lerner, Josh. 2009. Boulevard of Broken Dreams: Why Public Efforts to Boost Entrepreneurship and Venture Capital Have Failed and What to Do about It. The Kauffman Foundation Series on Innovation and Entrepreneurship. Princeton: Princeton University Press. RUSSOFT, 2014, Export of Russian Software Development Industry, RUSSOFT Association.

Schetnaya Palata Rossiyskoy Federatsii [Audit Chamber of Russian Federation]. 2014. “Otchet O Rezul'tatakh Kontrol'nogo Meropriyatiya «Audit Effektivnosti Ispol'zovaniya Gosudarstvennykh Sredstv, Napravlennykh Na Sozdanie I Razvitie Osobykh Ekonomicheskikh Zon» [Report on the Audit of Spendings of Public Money on the Creation and Development of Special Zconomic Zones]." http://www.ach.gov.ru/upload/iblock/388/388a2ebb69f74390241d6ac0e4aa82d9.pdf. 
—. 2015. “Otchet O Rezul'tatakh Kontrol'nogo Meropriyatiya «Proverka Obosnovannosti, Rezul'tativnosti I Effekt Ivnosti Ispol'zovaniya Byudzhetnykh Sredstv, Vydelennykh v 2011 - 2014 God Akh Na Realizatsiyu Kompleksnoy Programmy «Sozdanie v Rossiyskoy Federatsii Tekhnoparko v v Sfere Vysokikh Tekhnologiy» [Report the Inspection of the Effectivness of Utilisation of Public Money on Programm 'Creation of Technoparks in Russian Federation' in 2011-2014].” http://www.ach.gov.ru/upload/iblock/f25/f25a17d3f36bb72bdc6214c50f9bc60d.pdf.

Tatarchenko, Ksenia. 2013. “'A House with the Window to the West': The Akademgorodok Computer Center (1958-1993).” PhD diss., Princeton University.

Yevtushenko, Nina. 2003. "On One of the Branches of Cybernetics in Tomsk [Ob Odnoy Vetvi Tomskoy Kibernetiki].” Tomsk State University Journal 278: 43-45. 